\title{
MUSEU DE IMAGENS DO INCONSCIENTE: MOVIMENTO MODERNISTA, ARTES PLÁSTICAS E SAÚDE MENTAL
}

\section{ENSAIO TEÓRICO}

SILVA, Joseane Maria Pereira da ${ }^{1}$

CANDIDO, Lorraine Suelen de Oliveira ${ }^{2}$

SILVA, Joseane Maria Pereira da. CANDIDO, Lorraine Suelen de Oliveira. Museu de Imagens do Inconsciente: Movimento Modernista, Artes Plásticas e Saúde Mental. Revista Científica Multidisciplinar Núcleo do Conhecimento. Ano 05, Ed. 06, Vol. 01, pp. 145-158. Junho de 2020. ISSN: 2448-0959, Link de acesso: https://www.nucleodoconhecimento.com.br/psicologia/museu-de-imagens

\section{RESUMO}

Com o intuito de provocar uma discussão sobre o início do uso das artes plásticas como forma de tratamento em doentes mentais graves no Brasil irar-se-á articular o Movimento Modernista de Arte com base nas exposições e mostras de arte produzidas pelos pacientes do Centro Psiquiátrico Nacional, nos anos de 1946 a 1949, frutos do trabalho e tratamento psiquiátrico inovador, conduzido pela médica psiquiátrica Dra. Nise da Silveira. Para isso, fundamenta-se por meio de algumas discussões provocadas pelos críticos de arte Mário Pedrosa e Quirino Campofiorito, que protagonizaram verdadeiras batalhas epistemológicas de valor artístico das obras nos veículos de comunicação da época. Além de, também debater os fatos que

\footnotetext{
${ }^{1}$ Mestranda em Patrimônio, Cultura e Sociedade pela Universidade Federal Rural do Rio de Janeiro (UFRRJ-IM/PPGPaCS), Nova Iguaçu - RJ; Graduada em Psicologia UNESA, Nova Iguaçu - RJ; Pós-graduada em Psicologia Social e Pós-Graduada em Psicologia da Saúde pela UniBF, Joinville - SC.

${ }^{2}$ Graduada em Psicologia - UNESA, Nova Iguaçu - RJ; Graduada em Direito UFRRJ-IM, Nova Iguaçu - RJ.
} 
antecederam a fundação do Museu de Imagens do Inconsciente no ano de 1952. O objetivo é refletir sobre as benesses que esses fatos em conjunto proporcionaram para o movimento artístico, para a sociedade e para os avanços dos tratamentos em saúde mental.

Palavras-chave: Nise da Silveira, Movimento Modernista, Mário Pedrosa, Quirino Campofiorito, Museu de Imagens do Inconsciente.

\section{INTRODUÇÃO}

O presente artigo busca articular a história de vida da psiquiatra Nise da Silveira (2.1) e os desdobramentos que seu tratamento revolucionário constituiu para a medicina psiquiatra através das artes plásticas e os fatores de valores artísticos atribuídos por Mário Pedrosa e Quirino de Campofiorito em relação às obras de arte produzidas pelos internos do Centro Psiquiátrico Nacional e sua relação com o Movimento Modernista de Arte (2.2). Além de também expor um breve histórico dos acontecimentos que antecederam a fundação do Museu de Imagens do Inconsciente, fundado por Nise (2.3).

No primeiro momento desse estudo busca-se aprofundar o histórico de vida da Dra. Nise da Silveira, uma alagoana, casada com um colega da Faculdade de Medicina, onde estudou na Bahia entre os anos de 1926 e 1931. Foi uma das primeiras mulheres a se formar em medicina no Brasil. A história de vida de Nise é marcada por vários acontecimentos revolucionários, principalmente quanto à medicina psiquiátrica. Depois que seus pais faleceram em Maceió, ela e o marido se mudam para o Rio de Janeiro em busca de mais oportunidades de trabalho. Em 1933, depois de ser aprovada em um concurso público Nise começa a trabalhar no Hospital da Praia Vermelha, na área de psiquiatria. Devido à leitura de livros considerados aversivos e de caráter comunista na época, por conta de uma denúncia, foi presa política na ditadura do presidente Getúlio Vargas. Depois de liberta passou entre os anos 1936 e 1944 trabalhando quase que clandestinamente junto ao seu marido (BIERNATH, 2017). 
Após ser anistiada e regressar ao serviço público, desta vez no Centro Psiquiátrico Nacional, no bairro de Engenho de Dentro, no Rio de Janeiro (1946), por não concordar com os métodos de tratamento agressivos que a psiquiatria da época exigia, foi transferida como forma de punição, para o setor de Terapia Ocupacional, que era uma área pouco privilegiada nos setores do hospital. Essa transferência na verdade foi o marco para que Nise pudesse colocar em prática e estudar novas maneiras de tratamento psicológico. A Dra Nise da Silveira admitia: "Optei por utilizar como método a terapêutica ocupacional, método considerado de importância menor e até mesmo subalterno. Contudo, minha intenção primeira era de reformá-lo completamente. E assim fiz, [...]" (SILVEIRA, 1998, p.29).

Seus estudos e sua Seção de Terapêutica Ocupacional e Reabilitação (STOR) revolucionou o tratamento em doentes mentais, proporcionando o entendimento dos procedimentos do inconsciente psicológico e a cura através das expressões artísticas da pintura, desenho e escultura que os ateliês de artes plásticas permitiam. O pesquisador Walter Melo complementa: "[...] o método que começava a se esboçar ultrapassou a simples intenção de entrar em contato com o mundo de pessoas encerradas naquele triste local, pois o ato de plasmar imagens mostrou-se terapêutico em si" (MELO, 2009, p. 45).

Já num segundo momento desse trabalho, o Museu de Imagens do Inconsciente é o foco de debates e discussões que servem para entender a importância que o Museu repercute até os dias de hoje tanto para as práticas clínicas de tratamento em doentes mentais quanto para a comunidade científica internacionalmente. O Museu de Imagens do Inconsciente tem a maior e mais diferenciada coleção do gênero no mundo. É detentor do Registro Mundial no Programa Memória do Mundo da UNESCO - Organização das Nações Unidas para Educação, a Ciência e a Cultura - e têm obras de seus internos tombadas pelo IPHAN - Instituto do Patrimônio Histórico e Artístico Nacional (BIERNATH, 2017).

O acervo do Museu é constituído por mais de trezentos e sessenta mil obras, incluindo pinturas, desenhos e modelagens, produzidas e originadas por pacientes com doenças mentais desde 1946. Para Nise (1981, p.11), "a criatividade [...] por seu 
intermédio, sensações, emoções, pensamentos, são elevados a reconhecerem-se entre si, a associarem-se, e mesmo tumultos internos adquirem forma".

No terceiro momento desse estudo buscar-se-á a compreensão de alguns eventos que antecederam a fundação do Museu de Imagens do Inconsciente, inaugurado em 1952 e os debates de alguns críticos de arte, como Mário Pedrosa e Quirino Campofiorito que detinham uma compreensão oposta dos valores artísticos das obras dos internos do Centro Psiquiátrico Nacional. Na época, houve bastantes inquietações entre os críticos de arte, principalmente a respeito de atribuições de valor artístico nas obras dos internos de Engenho de Dentro (DIONÍSIO, 2001).

Um desses eventos foi à exposição organizada por Nise da Silveira em 1947, que tomou grandes proporções ao ponto de ser transferida para o prédio do Ministério da Educação, no Rio de Janeiro. Totalizando 245 pinturas de crianças e adultos, frequentadores da seção de terapêutica ocupacional, mediada por Nise. Para o crítico de arte Mário Pedrosa, nunca houve dúvidas, o que se via ali era arte. $\mathrm{O}$ crítico em suas publicações sobre arte, na época, não só atribuiu valor artístico como também relacionou ao conceito de Arte Moderna, realçando a inclusão da subjetividade do artista, a partir da Psicologia Moderna. Campofiorito foi um dos críticos que negou veemente a existência de valor artístico nas obras dos internos e também levanta críticas quanta à formação artística dos alienados (DIONÍSIO, 2001; FERREIRA e DA SILVA, 2017).

Os dois críticos levantaram verdadeiras batalhas epistemológicas nos jornais e revistas quanto aos conceitos de arte e valor artístico por conta da produção dos internos do Centro Psiquiátrico Nacional, dirigido por Nise. Discussões essas, que causaram grandes inquietações no período do Movimento Modernista de Arte. Para Campofiorito só podia ser observado à prioridade científica na leitura das obras e não a essência artística, já que os internos não tinha nenhuma formação acadêmica de valor artístico (DIONíSIO, 2012).

Contradições à parte, o Museu de Imagens do Inconsciente e a Seção de Terapêutica Ocupacional da Dra. Nise da Silveira, possibilitou o surgimento de vários artistas e 
exposições consagradas no meio artístico, principalmente em museus de conceitos modernistas. Como a exposição em 1949, na época o maior símbolo modernista nacional, o Museu de Arte Moderna de São Paulo, com a mostra chamada "9 artistas de Engenho de Dentro" (DIONísIO, 2012).

A partir dos elementos supracitados esse estudo irá permitir uma visão mais ampliada a respeito dos eventos que antecederam e contribuíram para a fundação do Museu de Imagens do Inconsciente e para a visão modernista que as obras ali produzidas foram relacionadas. Além da história de vida da Dra. Nise da Silveira, a forma de tratamento introduzida por ela nos internos do Centro Psiquiátrico Nacional determinaram a admiração e o consenso histórico de que Nise foi uma das pessoas mais importantes para a revolução do tratamento psiquiátrico no Brasil e mundialmente. Nise é referência em terapia ocupacional em qualquer lugar do mundo quando se fala em introdução de artes plásticas e tratamento psicológico em doentes mentais graves e esquizofrênicos.

\section{DESENVOLVIMENTO}

\subsection{BREVE HISTÓRIA DA VIDA DA PSIQUIATRA NISE DA SILVEIRA}

Nise da Silveira nasceu em Maceió, capital do estado de Alagoas, no dia 15 de fevereiro de 1905 e faleceu no Rio de Janeiro no dia 30 de outubro de 1999, foi uma médica psiquiatra, aluna de Carl Jung, o pai da Psicologia Analítica e um importante cientista das ciências psicológicas. Filha de Faustino Magalhães da Silveira, professor de matemática e Maria Lídia da Silveira, uma pianista. Nise foi admitida na Faculdade de Medicina da Bahia (1926-1931), com apenas 21 anos, sendo a única mulher entre os 157 homens da turma. É uma das primeiras mulheres do país a ter formação em medicina. Casou-se com seu colega de faculdade, o sanitarista Mário Magalhães da Silveira, convivendo com o mesmo até 1986, ano de seu falecimento. O casal optou por não ter filhos para se dedicarem de forma demasiada à carreira médica. Nise era manifestante declarada contra os tratamentos agressivos na psiquiatria de sua época, dentre esses: o eletrochoque, lobotomia[3] e encarceramento em hospitais 
psiquiátricos, também foi pioneira em observar o vínculo terapêutico entre pacientes e interações com animais (BIERNATH, 2017).

Em 1932, já órfã de mãe e sofrendo por conta do falecimento do seu pai, casada e formada, Nise e seu marido resolveram se mudar para o Rio de Janeiro, na época capital federal, onde acreditavam ter mais oportunidades de trabalho. Já estabelecidos no Rio, se engajaram nos movimentos artísticos e literários da área médica, com muitas publicações sobre os avanços da medicina (CÂMARA, 2002).

No ano de 1933, logo depois do término de sua especialização, foi aprovada em um concurso público na área de psiquiatria, começando a trabalhar no Serviço de Assistência a Psicopatas e Profilaxia Mental do Hospital da Praia Vermelha (COSTA, 2016).

Em 1934, denunciada por uma enfermeira pela posse de livros de caráter marxista, Nise da Silveira foi levada a prisão, no presídio Frei Caneca por quase dois anos. $\mathrm{Na}$ época, durante o Estado Novo de Getúlio Vargas, então presidente do Brasil, o envolvimento e simpatia por ideários comunistas Ihe custou sua liberdade. Durante a prisão teve como companheira de cela, a militante Olga Benário, que foi uma revolucionária comunista alemã, acusada de fazer parte do movimento Intentona Comunista - uma tentativa de golpe militar promovida pela Aliança Libertadora Nacional, contra o governo de Getúlio Vargas - Olga também foi esposa de Luiz Carlos Prestes, deportada para a Alemanha Nazista em 1936, onde morreu em uma câmara de gás em um campo de extermínio em 1942. Nise também conheceu na prisão o escritor Graciliano Ramos, tornando-se uma das personagens do seu livro Memórias do Cárcere, onde fez alguns relatos sobre a médica (BIERNATH, 2017).

Depois de libertada, entre 1936 e 1944, Nise e o marido permaneceram trabalhando quase clandestinamente, foi afastada do serviço público por motivos políticos. Ainda em 1944, foi reintegrada ao serviço público, desta vez no Centro Psiquiátrico Nacional, o antigo Centro Psiquiátrico do Rio de Janeiro, no bairro de Engenho de Dentro. Nise se recusava a seguir o tratamento psiquiátrico da época, entre esses: choque elétrico, isolamento e camisa de força. Por conta de sua recusa, a médica psiquiatra foi 
transferida para uma ala menos prestigiada como forma de punição, o setor de Terapia Ocupacional. No entanto, essa transferência foi primordial para o impacto que a psiquiatra provocaria na medicina psiquiátrica. Em 1946, nesse setor, junto do também psiquiatra, Fábio Sodré, os dois implementaram no hospital a Seção de Terapêutica Ocupacional e Reabilitação no tratamento psiquiátrico (BIERNATH, 2017).

$\mathrm{Na}$ STOR, Nise, criara ateliês de pintura e modelagem com intuito de promover aos doentes vínculos com a realidade sob a forma da expressão criativa e simbólica, provocando uma revolução da Medicina Psiquiátrica praticada no Brasil naquele período. Ela usara a arte como forma de tratar graves problemas de saúde mental. Nise percebera que as artes plásticas poderia ser o canal de comunicação com os pacientes esquizofrênicos graves, que até então não se comunicavam verbalmente (CÂMARA, 2002). A Dra. Nise complementa:

Decerto aquelas imagens revelam estranhos estados do ser, que não se deixavam apreender dentro do modelo médico adotado pela psiquiatria vigente. A psiquiatria descritiva não dispõe de definição tão exata para transmitir a dramaticidade dessas estranhas vivências. Limita-se a fazer a enumeração de sintomas "básicos" ou "acessórios" da esquizofrenia, como um rol de fenômenos mais ou menos indiferentes (SILVEIRA, 1998, p. 31).

Então, em 1952, ela funda um centro de estudo e pesquisa que se destina a preservar os trabalhos produzidos nos estúdios de pintura e modelagem que criou no Centro Psiquiátrico Nacional, que posteriormente se chamará Centro Psiquiátrico Pedro II, e que atualmente se chama Instituto Municipal Nise da Silveira, com intuito de valorizar as produções artísticas como documentos que abriu novos caminhos e possibilidades para uma compreensão mais aguda a respeito do universo dos doentes mentais, chamando-o de Museu de Imagens do Inconsciente, em Engenho de Dentro, no Rio de Janeiro (COSTA, 2016). 


\subsection{MUSEU DE IMAGENS DO INCONSCIENTE: ARTES PLÁSTICAS E SAÚDE MENTAL}

O Museu de Imagens do Inconsciente na verdade é uma ampliação das obras produzidas nos ateliês de pintura da Seção Terapêutica Ocupacional do Centro Psiquiátrico Nacional, tendo Nise da Silveira como diretora. Atualmente o Museu é um centro vivo e dinâmico de pesquisa e estudo sobre as obras, além de ter caráter interdisciplinar permitindo a troca permanente entre a prática clínica e saberes teóricos de psiquiatria, psicologia, história, antropologia cultural, arte e educação (COSTA, 2016).

O acervo do Museu é constituído por mais de trezentos e sessenta mil obras, incluindo pinturas, desenhos e modelagens, produzidas e originadas por pacientes com doenças mentais desde 1946. O Museu até os dias de hoje, produz diariamente em seus ateliês novas obras através dos seus frequentadores que compartilham experiências e convívio com animais, estudantes, pesquisadores, funcionários e visitantes (CÂMARA, 2002).

Além de produzir as obras, o Museu abriga o Instituto Municipal Nise da Silveira que organiza exposições, promove cursos, reúne grupos de estudos e oferece aos interessados campo de pesquisa, biblioteca especializada e estudo de casos clínicos. O Instituto Municipal Nise da Silveira e o Museu de Imagens do Inconsciente na verdade é o antigo Centro Psiquiátrico Nacional e/ou Centro Psiquiátrico Pedro II. Atualmente ainda é localizado no mesmo endereço em Engenho de Dentro, um bairro da zona norte do Rio de Janeiro (COSTA, 2016).

O principal objetivo de Nise da Silveira com as produções das obras dos pacientes era promover pesquisas sobre os procedimentos psicóticos através das figuras simbólicas que as artes plásticas proporcionavam. Seu interesse era a compreensão do que transcorria no mundo interno daqueles indivíduos tão herméticos, cuja linguagem verbal, era desagregada e neológica, tornando difícil a comunicação (CAMPOS, 2014). 
No entanto, essas obras aguçaram o interesse de vários críticos de arte e artistas, por conta dos seus resultados qualitativos que criara. Entre os críticos de arte que se sentiram provocados pela estética dos trabalhos produzidos nos ateliês de artes conduzidos por Nise, destaca-se Mário Pedrosa, que acompanhara de perto essas produções, denominando-as "arte virgem", ou arte ingênua e espontânea dos alienados (FERREIRA e DA SILVA, 2017).

No período do Movimento Modernista de Arte, a exposição dessas obras, causaram bastantes inquietações entre os críticos de arte, principalmente a respeito de atribuições de um valor artístico às manifestações de pessoas com diagnóstico de doenças mentais. Entre esses críticos de arte, Mário Pedrosa foi um dos que acreditou existir atribuição de valor artístico nessas obras e ainda relacionou-as ao conceito de Arte Moderna, ressaltando a inclusão da subjetividade do artista a partir da Psicologia Moderna. O crítico de arte, Quirino Campofiorito, foi um dos especialistas que negaram existir valores artísticos nas obras, defendendo somente a prioridade científica na leitura das obras, negando base artística. No decorrer desse estudo veremos mais um pouco sobre as discussões de valor artístico moderno entre Quirino Campofiorito e Mário Pedrosa em relação às obras de arte produzidas pelos frequentadores das seções de terapêutica ocupacional, dirigidas pela Dra. Nise da Silveira (CAMPOS, 2014).

Contradições à parte, o Museu de Imagens do Inconsciente possibilitou o surgimento de vários artistas que foram reconhecidos no mundo das artes. Seu acervo cresce e se atualiza constantemente. Para Ferreira \& Da Silva (2017, p. 7210), "além do olhar voltado à subjetividade do artista, as obras do Museu de Imagens do Inconsciente apresentam uma incrível semelhança com a qualidade estética de artistas modernos consagrados".

Mas para toda essa consagração do Museu de Imagens do Inconsciente e de seus artistas, é claro, muita coisa aconteceu durante os anos de 1946 até a sua inauguração em 1952. Para sanar essa lacuna histórica de informações e entendermos mais sobre os eventos que antecederam o Museu, o próximo tópico do estudo irá contar de forma objetiva e clara os episódios que consagraram a magnitude 
do Museu de Imagens do Inconsciente, um local de aspecto singular e de importância incalculável para uma nova postura de tratamento psiquiátrico no Brasil e no mundo (MELO, 2009).

\subsection{MUSEU DE IMAGENS DO INCONSCIENTE E O MOVIMENTO MODERNISTA DE ARTE}

Após Nise da Silveira assumir a diretoria da Seção de Terapêutica Ocupacional, por conta da sua negação em usar métodos mais agressivos como forma de tratamento em pacientes com transtornos mentais, optou por métodos mais psicossociológicos de tratamento, dando uma maior importância ao processo de cura utilizando atividades mais expressivas, criando o ateliê de artes plásticas no dia 09 de setembro de 1946 (CÂMARA, 2002; MELO, 2009).

Depois de noventa dias de pleno funcionamento, a produção de trabalhos foi tão intensa, que já existia material satisfatório para que fosse realizada a primeira mostra de artes. Então, no dia 22 de dezembro de 1946, foi inaugurada a primeira exposição de imagens do Centro Psiquiátrico Nacional. Com o total de participação de vinte adultos e quinze crianças frequentadoras das atividades das seções de pinturas (DIONÍSIO, 2001).

Houve tanto interesse pela mostra que as imagens tiveram que ser transferidas para o prédio sede do Ministério da Educação, no Rio de Janeiro com intuito de facilitar as visitas do público interessados no tema (DIONíSIO, 2001).

Por conta da proporção dos acontecimentos foi organizada uma segunda mostra no dia 04 de fevereiro de 1947. As duas exposições aconteciam ao mesmo tempo e no mesmo local, continuou situada no prédio do Ministério da Educação, no Rio de Janeiro, dessa vez instalada no grande salão do andar principal. Além de conter as obras expostas na primeira pequena exposição de 1946, havia também telas de trabalhos mais recentes, totalizando duzentos e quarenta e cinco pinturas de crianças e adultos. Mais uma vez, essa mostra desperta bastante impacto nos meios culturais, artísticos e científicos. Múltiplos artistas publicaram notas e artigos sobre a exposição, 
dentre quais destaca-se Mário Pedrosa no jornal impresso, Correio da Manhã, e Quirino Campofiorito, O Jornal (DIONíSIO, 2001). Outros autores cronistas que contribuíram com narrativas sobre a exposição foram: "Rubem Navarra, no Diário de Notícias, Marc Berkovitz, no Brazil-Herald e Antônio Bento, no Diário Carioca" (DIONÍSIO, 2001, p.02).

Para Mário Pedrosa nunca houve dúvidas: tratava-se de arte. No entanto, mais tarde, o crítico sentiu a necessidade de ser mais preciso quanto às ideias no que concerne às imagens que habitavam na mostra, contrastando nelas o tom de frescor e novidade, chamando-as de arte virgem (DIONíSIO, 2012). O primeiro contato que o crítico de arte Mário Pedrosa teve com os trabalhos de pinturas dos pacientes de Nise da Silveira, foi na mostra organizada em 1947. Segundo seu colega e poeta Ferreira Gullar, Pedrosa deslumbrou-se com as obras ali vistas (GULLAR, 1996, p. 20). Sob patrocínio da Associação dos Artistas Brasileiros, Pedrosa, em 31 de Março de 1947, faz o encerramento da exposição dando uma conferência intitulada: "Arte, necessidade vital" (PEDROSA, 1996). Generalizando, nessa conferência, o crítico de arte, traz os seus primeiros comentários favoráveis ao valor artístico encontrado nas obras daqueles pacientes (DIONÍSIO, 2001).

Apesar de muitos, como Quirino Campofiorito contradizer e negar que as obras da mostra não tinham valor artístico e muito menos se pensara ser modernistas, logo após a conferência que Pedrosa fechara, a exposição dos pacientes de Engenho de Dentro, as esculturas e telas que ali estavam em exposição foram transferidas para o Museu Nacional de Belas Artes, o maior museu de referência de arte do Brasil (CAMPOS, 2014).

Trazido por Mário Pedrosa, em 1949, Leon Degand, foi levado para conhecer as oficinas e ateliês do Centro Psiquiátrico Nacional. Leon Degand, na época, além de crítico de arte, também era diretor do Museu de Arte Moderna de São Paulo. Durante a visita, Leon Degand, ficara tão impressionado pela qualidade artística de muitos trabalhos realizados ali, que segundo Nise, o próprio Degand propôs ao Centro Psiquiátrico que expusesse os trabalhos produzidos em São Paulo, no Museu de Arte 
Moderna (SILVEIRA, 1966). Mais uma vez, foi organizada a segunda grande exposição de pinturas dos artistas de Engenho de Dentro (DIONíSIO, 2012).

O próprio Degand com a ajuda de Mário Pedrosa selecionou os trabalhos para a exposição. Ao regressar de Paris, no dia 12 de julho de 1949, Degand foi substituído por Lourival Gomes Machado, também crítico de arte, na Diretoria do Museu de Arte Moderna de São Paulo. Lourival também é um dos que não negou encontrar bases de valor artístico nas pinturas dos artistas de Nise da Silveira. Então, no dia 12 de outubro de 1949, com o nome de "9 artistas de Engenho de Dentro" a exposição é inaugurada no principal salão do Museu de Arte Moderna de São Paulo (DIONÍSIO, 2012).

Dentre os artistas e pacientes que participaram da exposição, os que mais se consagraram na arte de pintar foram Emydgio de Barros e Raphael Domingues, os outros foram, Carlos, Kleber, Adelina, Carlos, Lúcio, Vicente e Wilson. O número de artes expostas somou 179, dentre pinturas, desenhos e esculturas (DIONÍSIO, 2012).

Como esperado, a exposição de 1949, assim como a de 1947, obteve grandes repercussões nos jornais e revistas da época. Destacando às crônicas de Sérgio Milliet no Estado de São Paulo e Quirino da Silva no Diário de São Paulo. Mais uma vez, Campofiorito, no Diário da Noite e O Jornal, e Pedrosa, no Correio da Manhã, travam um debate de grandes proporções a respeito do valor artístico e modernistas nas obras dos pacientes, principalmente na exposição de 1949 (CAMPOS, 2014).

Como revelado anteriormente, Pedrosa encontrava nas pinturas dos internos de Engenho de Dentro, qualidades genuínas de valor artístico, no entanto, como também, já dito, Campofiorito às negava. Para Quirino as produções dos artistas do Centro Psiquiátrico só podiam ser categorizadas como prioridade científica a partir da leitura das obras expostas. Já, Mário, designou de maneira original a produção dos pacientes, introduzindo a conceitualização de "arte virgem". Campofiorito negou qualquer vínculo de propriedade artística e estética naquelas obras (DIONÍSIO, 2012; CAMPOS, 2014) 
O fato é que as obras dos internos de Engenho de Dentro, deslumbrou tanto a Mário Pedrosa, que no mesmo ano, de 1949, Pedrosa textualiza a tese "Da natureza efetiva da forma na obra de arte" (PEDROSA, 1996), contribuindo mais uma vez nas fundamentações de discussões que envolvem arte e psicologia (DIONÍSIO, 2012).

No mesmo ano, em 1949, a exposição foi exposta no Salão Nobre da Câmara Municipal do Rio de Janeiro. De acordo com Nise da Silveira, esse evento foi o que gerou as maiores repercussões, tanto em número de visitações quanto em vinculações na imprensa. Foi notório também o grande número de autores de crônicas, artigos e editores da imprensa em defesa da integridade artística dos internos e do valor artístico nas obras (DIONíSIO, 2001).

A ideia do Museu vai tomando corpo à medida que amplia a numerosidade de trabalhos das sessões terapêuticas de Nise da Silveira sendo divulgados. Então, no dia 20 de maio de 1952, o Museu de Imagens do Inconsciente é fundado pela Dra. Nise da Silveira com uma singela mostra dos trabalhos dos internos (CAMPOS, 2014).

Para termos uma ideia da proporcionalidade da esfera que o trabalho da Dra. Nise e da consagração artística que os internos foram intitulados, há um episódio de caráter internacional que foi bastante relevante nessa gênese. Foi a participação do ateliê no II Congresso Nacional de Psiquiatria, em Zurique em 1957 inaugurada por Carl Gustav Jung, considerado o pai da Psicologia Analítica, e que também trocava correspondência com Nise sobre as obras e seus métodos de tratamento desde o surgimento das sessões de terapêutica ocupacional no Centro Psiquiátrico Nacional (DIONÍSIO, 2001).

Atualmente o Museu de Imagens do Inconsciente tem a maior e mais diferenciada coleção do gênero no mundo. A importância é tanta, que as principais obras do Museu são tombadas pelo IPHAN. Também guarda o arquivo pessoal e a biblioteca de sua fundadora, Dra. Nise da Silveira. O Museu é detentor do Registro Mundial no Programa Memória do Mundo da UNESCO (BIERNATH, 2017). 


\section{CONSIDERAÇÕES FINAIS}

Apesar de críticos como Quirino Campofiorito, as obras do Museu de Imagens do Inconsciente, para muitos apresentam semelhanças com a qualidade estética de artistas modernos. Como vimos, Mário Pedrosa era um dos muitos críticos que não tinha dúvidas quanto ao valor artístico das obras dos internos de Engenho de Dentro.

O que observamos é que tanto a negação, quanto a afirmação do valor artístico e as grandes exposições que essas obras tiveram, foi importante pelo menos para uma coisa: enfim, havia espaço para debates contrários ou benéficos a respeito dos trabalhos dos usuários em saúde mental da época. De alguma forma, a Dra. Nise da Silveira conseguiu uma mobilização de críticos, teóricos, jornais, revistas e cientistas que falassem sobre uma população tão estigmatizada.

Começava ali o que chamamos hoje de inclusão psicossocial de pessoas com transtornos mentais através das artes plásticas no país, afinal "eles estavam na moda". A cada exposição e mostra pública de artes e obras dos internos do Centro Psiquiátrico Nacional causava um alvoroço, inquietações, discussões que beneficiaram a introdução de internos dos serviços de saúde mental, antes excluídos das vivências em sociedade.

Se as obras realmente eram modernistas e/ou tinham valor artístico tudo isso fica em segundo plano quando observamos a sagacidade de Nise da Silveira ao incluir no imaginário e discussões sociais o doente mental e uma nova maneira revolucionária de tratamento psicossocial através das artes plásticas.

\section{REFERÊNCIAS}

BIERNATH, André. Você precisa conhecer a história de Nise da Silveira. Revista eletrônica Veja Saúde - Medicina. 2017. Disponível: $<$ https://saude.abril.com.br/blog/tunel-do-tempo/voce-precisa-conhecer-a-historia-denise-da-silveira/> Acesso em: 03/01/2019. 
CÂMARA, Fernando Portela. História da Psiquiatria: vida e obra de Nise da Silveira. Psychiatry on line Brasil - Vol.7 - ำ9. Setembro de 2002. Disponível em: <http://www.polbr.med.br/ano02/wal0902.php> Acesso em: 05/01/2019.

CAMPOS, Beatriz Pinheiro de. Quirino Campofiorito e Mário Pedrosa: entre a figuração e a abstração. A crítica de arte e o surgimento da arte abstrata no Brasil (1940 a 1960). Dissertação (Mestrado em História) - Instituto de Ciências Humanas, Universidade de Federal de Juiz de Fora. Minas Gerais, 2014.

COSTA, Carlos. Sobre Nise da Silveira e o ateliê de Engenho de Dentro. Revista Eletrônica Itaú Cultural: São Paulo. Publicado em 28/12/2016. Disponível em: $<$ https://www.itaucultural.org.br/sobre-nise-da-silveira-e-o-atelie-de-engenho-dedentro> Acesso em: 05/04/2020.

DIONÍSIO, Gustavo Henrique. Museu de Imagens do Inconsciente: considerações sobre sua história. Revista Psicol. cienc. prof. vol.21 no.3 Brasília Set. 2001. Disponível em: http://www.scielo.br/scielo.php?script=sci_arttext\&pid=S141498932001000300005\#ast1b Acessado em 02/01/2019.

DIONíSIO, Gustavo Henrique. Flores do abismo, imagens do inconsciente. Linguagens - Revista de Letras, Artes e Comunicação. ISSN 1981-9943 Blumenau, v. 6, n. 2, p. 215-233, mai./ago. 2012.

FERREIRA, Anny Lemos; DA SILVA. José Marcos Romão. As obras pictóricas do museu de imagens do inconsciente e suas afinidades com a pintura moderna. Revista UNESP. São Paulo. 2017.

GULLAR, Ferreira.; Silveira, Nise da. Uma psiquiatra rebelde. Rio de Janeiro: Relume-Dumará, 1996.

MELO, Walter. Nise da Silveira e o campo da saúde mental (1944-1952): contribuições, embates e transformações. Mnemonise, v.5, n.2, p.30-52, 2009. 
PEDROSA, Mario. Obras escolhidas, Vol. Il: Forma e percepção estética. Em Arantes, O. (org.) São Paulo: Ed. da Universidade de São Paulo. 1996.

SILVEIRA, Nise da. Imagens do Inconsciente. Rio de Janeiro: Alhambra, 1981. . Vinte anos de terapêutica ocupacional em Engenho de Dentro (19461966). Revista Brasileira de Saúde Mental. Rio de Janeiro, Vol. 5, XII no editado. 1996. . Gatos a emoção de lidar / Nise da Silveira; com fotos de Sebastião Barbosa - Rio de Janeiro: Léo Christiano Editorial, 1998.

\section{APÊNDICE - REFERÊNCIA DE NOTA DE RODAPÉ}

3. É uma intervenção cirúrgica que retira um pedaço do cérebro, geralmente o lobo pré-frontal, que é a área cerebral que mais se destaca no cérebro humano.

Enviado: Março, 2020.

Aprovado: Junho, 2020. 